\title{
IMPROVING ACCESS TO COLLECTIONS FOR SAMPLING
}

\author{
Jane Henderson and Panagiota Manti
}

\begin{abstract}
The commitment to increasing access to collections has resulted in concepts such as 'acceptable' rates of damage. This new pragmatism has yet to be developed into a consistent approach to access for analysis. This paper uses a case study of the scientific examination of early Greek copper alloy helmets to illustrate a range of problems encountered by researchers. In the context of the case study it considers national and political criteria, the policies and procedures of museums and professional ethical codes. The paper also considers additional barriers that can be encountered by younger researchers, who may be considered less credible than their more established colleagues, and discusses strategies that they can use to increase the likelihood of gaining access to samples.
\end{abstract}

\section{INTRODUCTION: ACCESS AND SAMPLING}

The concept of access to collections as something with an almost moral imperative has taken hold in recent time. Within this, many conservators have reconsidered their role in preserving collections from that of a relationship between conservator and material-object to one considering the needs and values of users and owners $[1,2]$. Embedded within the concept of access is the issue of use and the potential or actual damage that arises. It is possible to argue that all use leads to damage, even if only at a microscopic level. Access, use and damage are therefore all part of the same paradigm. A full discussion of the concept of damage has been covered elsewhere [3], but within this paper it is used to mean an observable degree of change that is considered unacceptable to at least one core stakeholder. The concept of accepting damage has become familiar to conservators dealing with light levels [4], ethnographic [5] and operating collections [6], yet it still causes some conservators to respond nervously.

This paper was inspired by the challenges and the generally positive response that one of the authors experienced in obtaining samples from collections of Greek helmets from a range of organizations, and focuses on one small aspect of access to collections. The specifics of the case study are summarized below and reported in greater detail elsewhere [7]. These experiences prompted a wider questioning of the attitude to invasive sampling from the conservation and wider museum profession. The paper discusses both structural and social issues that affect the decisionmaking process, discusses how individual researchers can best improve their chances of gaining access to samples for research and examines the role of conservators in creating a climate where permission for sampling may be given.

The aim of the paper is to offer support to researchers, especially those who have yet to establish their credibility, whose research requires invasive samples from material held in museums and similar collections. It may also serve as a reminder to conservators wishing to act as advocates for objects or collections, that communication is a skill that can be researched and improved by the careful consideration of the needs and priorities of those that they wish to influence.

In considering a communication, such as a request for samples, there are four key elements to the exchange:

\section{The nature of the institution}

2. The person to whom the request is addressed

3. The nature of the person making the request

4. The request; its content and method of delivery.

These elements can be simplified into context, receiver, source and message [8], and are discussed in turn below.

\section{CASE STUDY: GREEK HELMETS - SAMPLING FOR ANALYSIS}

The research project investigates the manufacturing technology, visual appearance and production of Greek copper alloy helmets of the Illyrian and Corinthian type from the early Archaic to the Classical period. Taking into account their typology, chronology and provenance, the programme examines regional workshop practices and patination phenomena on Hellenic helmets. Analysis relies heavily on scientific methods that require sampling: metallography and scanning electron microscopy with wavelength dispersive X-ray spectroscopy. These methods are described as invasive or destructive towards the object, but non-destructive towards the sample, as this may be used in future investigations. Where possible, synchrotron and neutron-based non-destructive analytical techniques were used. The nature of this project calls for permission to sample a large number of helmets. In total, the project has gained access to 150 objects with direct access to sample 120 helmets, following communications with 42 museum professionals in 13 museums in Greece and the UK. This success rate is in part due to the sampling protocol put in place to request samples, which is discussed below.

\section{REQUESTING SAMPLES: THE CONTEXT}

When developing a sampling strategy, a researcher must consider a range of factors that affect decisions to grant access. One of these relates to the country in which the collection is held. In this case study we consider European legislation and the situation in the United Kingdom and Greece.

\section{European legislation}

The Council of Europe expressed concern for the protection and enhancement of archaeological heritage in 1954 [9]. The London Convention of 1969 encourages access and collaborations for research on archaeological objects [10]. The use of both destructive and non-destructive scientific techniques is explicitly supported by the Malta convention [11], while later declarations identify principles to act as reference points for heritage research in Europe [12].

All states signing the European conventions are obliged to place the principles of the international agreements into practice and can do that according to their individual needs [13]. The result is a significant degree of variation in practice, as the cases of the UK and Greece illustrate. Researchers wishing to collect samples internationally should carry out research into the national practice before applying, and be prepared for a significant variation in protocol.

\section{The UK}

The heritage sector in the UK is highly decentralized. Each museum is responsible for its own access policies, based on professional guidelines. Across the UK, museums and universities are funded through a wide range of government departments, while independent museums raise money from the private sector. This general decentralization leads to a situation where there is no national policy in relation to sampling. The general European ethos of accessing collections is facilitated by a straightforward request to the owner presented in a format usually dictated by the museum itself. Permission for invasive sampling can be more difficult to obtain and often depends on the culture of 
the organization and the experience of individual stakeholders. Common procedure involves a study visit prior to sampling, and a written request setting out the purpose of the research, sampling rationale, sample size and analytical techniques. Each museum is then responsible for assessing the scientific basis of the application and proceeds to grant or refuse permission.

\section{Greece}

The international conventions in Greece are expressed within the national legislation in a centralized manner. The Ministry of Culture, through its regional departments (Ephories), is the main governmental body responsible for cultural heritage issues. Law number 3028/2002, amongst others, establishes legal provisions for the museum sector, stipulates public access and defines regulations for archaeological research [14]. This latter is further defined by specific ministerial regulations ( ГААПК/АРХ/А2/ Ф30/22268/778/5-3-2004) on the sampling of antiquities, which give details on the type of objects to be sampled for analysis and restrict invasive sampling to areas of fragmentation or missing parts. This centralized system allows little decision-making power to devolve to local authorities in relation to sampling permissions. It is the individual excavators, permanent staff of the Ministry of Culture, who hold the intellectual rights of the material and decide primary access for study. Common procedure involves written permission from the excavator and relevant director followed by a detailed application to the Ephoria, which passes it to a specialist division of the Ministry of Culture that decides each case on its merits.

Museum and professional conservation ethics and policies The need for invasive sampling is recognized by professional conservation bodies $[15,16]$ and museum organizations $[17,18]$. Codes of ethics tend to advise avoidance of invasive sampling when alternative non-invasive methods are available, and to take the minimum sample required. Professional bodies' guidelines incorporate the general ethos of international legislation and add that sampling requirements should also include owner consent, retention of samples and clear documentation of sample and object.

Ethical codes identify the need "to maintain a balance between the preservation of cultural property and the need to use, understand and appreciate it" [15]. The impact on the object and the "expected value of the information gained, must be weighed against the effect of removal of the sample upon the cultural property" [16]. Although there is an effort from professional conservation bodies to embed invasive sampling within codes of ethics, the ultimate decision to sample rests with the owner organization, allowing some inconsistency within the sector.

\section{Organizational culture}

In countries where the decision to approve sampling is decentralized, access to samples may depend on the culture of an organization. This can be highlighted by comparing national and university museums. Personal experience has shown that university museums exhibit greater flexibility in sampling requests than national organizations, both in bureaucracy and general response. This may be a result of university museums having a greater focus on research due to the core values of parent institution.

Tite recalls that it was much easier to obtain samples during the 1960s. An increase in formal sampling policies may be a direct result of past practice [19]. Increasing museum accountability has brought awareness of poor analysis regimes [20], and has required museums to seek assurance that the research is of a high standard, that the museum will benefit from the dissemination of the results and the results will allow better understanding of their collections. This attitude stems from past practice where samples and feedback on results were never returned [21].

\section{The Job factor}

Within each institution the professional background of the assessor of the application is important. Most often an application goes through a panel, including a curator/archaeologist, a conservator and perhaps an archaeological scientist. Each professional has expertise that can lead to contradictory interests in relation to an object. Conservators are traditionally interested in preserving the integrity of the object, archaeological scientists in the scientific validity of a project and curators in the knowledge outcomes. Decisions will be affected by differing professional perspectives and the position of each professional in the hierarchy of the institution. When a proposed research project competes with the research interests of a stakeholder, access may prove more difficult.

\section{THE RECEIVER OF THE SAMPLING APPLICATION}

Although an application for sampling is made to an organization, it is our experience that most researchers find that they need to persuade a person or a small group of people, so an analysis of the personal factors affecting decision making is valid. There are many personal factors that could be analysed [22], however, here we consider a selection appropriate to this case study: decision making, values and attitude to risk.

\section{Decision making}

Psychologists often distinguish between two aspects of decision making: how people ought to make decisions and how people actually make decisions [23]. Some go as far as to argue that people first make an unconscious decision based on their emotional response and then subsequently justify that decision in the light of the evidence presented [24]. It may be frustrating to realize, but a sampling request may not be considered rationally. To be successful, a strategy that goes beyond a reasoned appeal may be necessary.

In psychology literature, the term 'decision heuristics' describes the mental shortcuts that help people make decisions. Drummond [25, p. 183] identifies three areas that trigger these shortcuts:

\section{1. vividness}

\section{2. representativeness}

\section{3. anchoring and adjustment.}

A simple way to understand the impact of vividness is to consider the greater fear many people have of an aeroplane, rather than a car crash. This illustrates that facts alone (such as crash statistics) may not be the primary factor in decision making if a vivid image of consequences trips the simpler heuristic decision process. Representative heuristics relates to a decision maker deciding on a situation by its similarity to a previous one. Anchorage and adjustment relates to numerical elements in the decision. For example, if someone requests six samples from a helmet the owner will work up or down from that anchor point, adjusting it to a final agreed decision. The section below, 'the message', considers how all three factors could be influenced.

Rational decisions are based on the evaluation of an option against a set of objective criteria. Outcomes can be influenced by 'screening' the criteria under consideration to make the chosen outcome the most favourable one considered [25, pp. 155-157]. 'Decisionless decisions' can directly affect an application [25, p. 178]. The threat is that a decision will not be made within the research period, whether positive or negative. The consequence of a failure to make a decision becomes, in practice, a refusal. 


\section{Implied organizational values}

Although in well-established organizations, such as museums and universities, there is a tendency towards more formal and rigid decision-making structures [26, p. 192], decisions still fall to individuals. Even when no explicit written instructions exist, staff in an organization are highly influenced by the implied values of their institution and peers, through accepted norms and beliefs $[27$, p. $267 ; 26$, p. 180$]$. A researcher should try to identify the views of the individual decision makers and if that is not possible, try to infer their values from the words and actions of their organization. Where the researcher carries out a site visit to assess the collections, it may be easier to evaluate personal priorities rather than where the request is carried out entirely in writing.

\section{Attitude to risk}

Sampling artefacts for analysis is inherently risky; however skilled the sampling technique, the risk that the artefact will be damaged to a greater extent than predicted remains. There is also a possibility that the outcomes of the research project will not meet expectations; they may provide little evidence or the result may even challenge the current interpretation and value of the object. A good research proposal normally minimizes risk, but the receivers of the request may still evaluate it as risky.

People differ in their willingness to gamble, but there are some trends that can be examined using 'prospect theory'. This theory suggests that individuals are more risk-averse when they are holding on to what they already have, being more likely to take risks when choosing between certain losses [25, pp. 180-182; 27, p. 245]. One advantage of this attitude is that if analysis required more samples the researcher should consider requesting another sample (the owners would then be choosing between losses) and they may be allowed another attempt.

Prospect theory also argues that people are systematically biased in what evidence they consider, for example, they pay more attention to outcomes that they consider certain and ignore events that they consider improbable [25, p. 182]. This suggests that the certainty of the damage caused by sampling will be weighed up against the uncertainty of the benefit of the result. The more highly the receiver values research results, the more significantly this will counterbalance their aversion to the 'loss' of the sample.

It is also suggested that there are national trends in response to risk [26, p. 197]. Cultures that are described as having strong uncertainty avoidance will have a consequent reluctance to take risks [28]. The degree to which this risk aversion is reflected in national policies on cultural heritage might make an interesting study.

\section{THE SOURCE OF THE SAMPLING REQUEST}

Credibility is complex, multi-dimensional and situational [29, p. 90]; however, most authors define credibility as containing two key components: expertise and trustworthiness [29, pp 78-80;24, p. 101]. Expertise can be seen as a form of power, when other forms are not applicable [23], and is independent of the hierarchy of the organization. Therefore, a researcher's credibility and power will be evaluated largely on a critical assessment of their expertise by the receiver in relation to the topic in hand [30]. Credibility can also be defined as the attitude of the receiver to the source [31, p. 138]. Credibility and expertise can be lent to a request by adopting the status of others to endorse the request [31, p. 157]. This can take the form of co-workers, funders and supporters. Where requests are initially unsuccessful, developing this sort of expertise by association could be the key to establishing agreement.
The age and gender of the researcher must also be considered in relation to their credibility and to the receiver of the request [30]. Research shows that in many work environments women have to do more than male counterparts to achieve the same status and positive evaluation. Younger female researchers may find it harder to be positively evaluated than older male colleagues. Fortunately, when decision making involves a careful assessment of the facts, evidence becomes more significant than gender or age $[32 ; 29$, p. 81].

\section{THE MESSAGE: CONTENT OF THE SAMPLING REQUEST}

The purpose of describing decision theory is to consider how this may impact on a sample request. This section considers the elements of a request that should be provided to satisfy both the reasoned and the emotional expectations of receivers. A researcher should design the request to take into account the specific organization, its location and the individual decision makers involved.

\section{Essential elements of a request}

Any request must be framed by the specific legal factors with respect to the nationality of the owner. Beyond this, it is possible to suggest specific elements that should be contained within any such request, and comment upon the process.

Following the development of the research plan, a researcher should contact the museum, requesting access to the collections for study. In our case, the request outlined the proposed study, profiled the applicant and highlighted the importance of the samples requested within the project. A study visit followed to prepare a full application pack with documentation of each individual object identified as valuable for the research, Fig. 1. The application also stated that samples would be returned to the museum with relevant analytical results. Central to this application pack were images of each helmet examined during the first study visit, with details on their condition and technology and a

\begin{tabular}{|c|c|}
\hline \multirow{10}{*}{$\mathbf{A}$} & Proposal (content) \\
\hline & Aims and objectives of the project \\
\hline & $\begin{array}{l}\text { Project description including: } \\
\text { - scope } \\
\text { - } \text { the remiationship between the analysis and the expected outcomes } \\
\text { - selected bibliography }\end{array}$ \\
\hline & Significance of results \\
\hline & Benefits to the museum from the outcomes and collaboration \\
\hline & Project motivation and preliminary results (if any) \\
\hline & $\begin{array}{l}\text { Outline of proposed analytical research programme, with details of: } \\
\text { - the analytical methodology and techniques to be used, } \\
\text { - how these methods contribute to answering the questions set } \\
\text { - ceference to the availability and access to instrumentation } \\
\text { collations achieved for the use of particular instrumentation }\end{array}$ \\
\hline & $\begin{array}{l}\text { List with short description of objects for study and analysis with explanation of } \\
\text { particular benefits from examining selected items }\end{array}$ \\
\hline & Justification for sampling and sample selection \\
\hline & $\begin{array}{l}\text { High quality photographic documentation of selected objects for analysis, and } \\
\text { suggested sample locations }\end{array}$ \\
\hline \multirow[t]{8}{*}{ B } & Status (evidence) \\
\hline & Personal research experience and academic background \\
\hline & Personal credentials \\
\hline & The status of co-workers or supervisors \\
\hline & Other endorsements such as grants or support \\
\hline & Association with other successful projects \\
\hline & Evidence of acting in the best interests of the institution and their collections \\
\hline & Similarity to decision makers interests and concerns \\
\hline \multirow[t]{8}{*}{$\mathbf{C}$} & Contract (application pack and communication logistics) \\
\hline & Personal statement for the purpose of the application \\
\hline & Curriculum vitae \\
\hline & Proposal \\
\hline & $\begin{array}{l}\text { Arrangements for the return of samples (when non destructive analysis is } \\
\text { employed) }\end{array}$ \\
\hline & $\begin{array}{l}\text { Arrangements for the storage of samples during research, care and } \\
\text { documentation }\end{array}$ \\
\hline & Clarification of publication rights \\
\hline & Proposals for the dissemination of results \\
\hline
\end{tabular}

Fig. 1 Research request checklist. 
description of the suggested sampling areas. Sample sizes, sampling procedures and rationale were also reported. Respect for the minimum damage principle was demonstrated by restricting sampling requests to loose fragments, damaged edges, fractures and unobtrusive locations that avoid post-sampling restoration. Attention to the quality of images and presentation of the application pack is of great importance, as this will be taken as an indicator of the researchers' professionalism and their attention to detail, aesthetics, practical skills and responsibility will be inferred from it.

\section{Psychological factors in a request}

People often make decisions on an emotional basis, so a researcher should consider how the receiver's acquiescence to the request would satisfy the latter's needs. The essential elements in this case would include showing how agreeing to the request would provide the object's custodian with intellectual satisfaction, would be consistent with past behaviour, would recognize their status and may help others [33, pp. 23-24]. The following three actions can help satisfy the receiver's needs.

1. Present a vivid image of the successful project outcome and research the receiver's direct experience of similar projects. Has a previous researcher taken large and unnecessary samples without publishing? If so, stress the differences to the project in hand. Alternatively, if a researcher from your own organization carried out work with a positive outcome, stress the similarities. This will help with the representative heuristics and feed the increase in liking and therefore positive influence by association [34, p. 169]

2. If negotiation on the number or size of samples is possible, try to predict whether the request is likely to be successful or unsuccessful. Cialdini argues that if the chances of agreement are low the 'foot in the door technique' of asking for a small request and ratcheting it up once compliance is gained is most effective, and the 'door in the face' technique of asking for a lot and then 'compromising' down is most effective where success is likely [34, pp. 37-61].

3. Frame expertise carefully, for example, the curator at the museum may assess the researcher as low in expertise regarding that object type but may evaluate the researcher highly in relation to the analytical technique. Researchers should emphasize their strongest characteristic in relation to the receiver, through publication lists, examples of other similar materials worked upon, funding and awards. The researcher can also associate themselves with the expert power of others by citing co-workers and supervisors.

\section{Presenting risk}

Small changes to the way in which a risk is presented can change the way in which it is evaluated [35]. As a general rule, proposals should be presented as risk-free as possible [33, p. 34]. In the free text description of the project, the positive research outcomes that are certain should be stressed, for example, the prestige of participation in the project, increased knowledge of the collections and the benefits of partnership working, even if the specific outcome of the work cannot be stated. The 'loss' of a sample cannot be avoided, but losses from a lack of participation can also be stated to rebalance the pool of decision criteria in favour of the request. Describing sampling as damage will present it as a loss; describing it as increasing information and access may present it as a gain.
The contract

A museum would be more comfortable providing samples when the application takes the form of a contract. Issues that should be set out include: temporary storage of the samples, the return of samples for storage, documentation of the samples' condition and dissemination of results. Setting a time-frame for sample return is challenging because analysis often requires long procedures and evaluations. The written permission to sample and study should also legally cover issues of copyright and publication, Fig. 1.

\section{PROMOTING RESEARCH}

Those in a position of responsibility in institutions should review their role in facilitating requests for samples. In a climate where there are growing calls to increase the use of collections, to encourage research which builds 'links between museums and higher education' [36] and encouragement to use scientific research to understand cultural heritage [37], the door should be open to advocating support for research that includes sampling. Conservators and conservation scientists have the ethical vocabulary to make decisions that include accepting damage and have the skills to balance the costs and benefits from different levels of use, including sampling. Conservators can play an essential role in providing support to external researchers by acknowledging the value of research results, accepting that the procedures comply with ethical codes and standards of practice, and advocating for this form of access with their colleagues.

\section{ACKNOWLEDGMENTS}

We thank Mr David Watkinson for his constant support of this project, all those who supplied samples and Dr E. Pantos (Daresbury Laboratory) and W. Kockelmann (Rutherford Appleton Laboratory) for support with analysis.

\section{REFERENCES}

1 Drysdale, L., 'The eternal triangle: relationships between conservators, their clients, and objects', in Conservation today papers presented at the UKIC 30th Anniversary Conference1988, ed. V. Todd, UKIC, London (1988) 18-20.

2 Thorn, A., 'Tjurkulpa: A conservator learns respect for the land, the people and the culture', in The Object in Context: Crossing Conservation Boundaries, ed. D. Saunders, J.H. Townsend and S. Woodcock, IIC, London (2006) 133-137.

3 Michalski, S., 'Sharing responsibility for conservation decisions', in Durability and Change: the Science, Responsibility and Cost of Sustaining Cultural Heritage, ed. W.E. Krumbein, P. Brimblecombe, D.E. Cosgrove and S. Staniforth, John Wiley and Sons, New York (1994) 246-248.

4 Ashley Smith, J., Risk Assessment for object conservation, Butterworth-Heinemann, Oxford (1999) 241.

5 Pye, E., and Sully, D., 'Evolving challenges, developing skills', The Conservator 30 (2007) 28

6 Ball, S., Larger and Working Objects: A guide to their preservation and Care, ed. P. Winsor, Museums and Galleries Commission, London (1997) 24-26.

7 Manti, P., and Watkinson, D., 'Examination of Greek bronze helmets: sampling and project design', in Metal 07 Proceedings of the ICOM-CC Metal Working Group international triennial meeting, Amsterdam, ed. C. Degrigny, R. van Langh, I. Joosten and B. Ankersmit, Rijksmuseum, Amsterdam (2007) 78-82.

8 Henderson, J., 'New Skills New Influence', in Past Practice Future Prospects, ed. A. Oddy and S. Smith, British Museum Occasional paper 145, The British Museum Press, London (2001) 106.

9 Council of Europe, European Cultural Convention, European Treaty Series 18, Paris (1954)

10 Council of Europe, European Convention on the Protection of the Archaeological Heritage, European Treaty Series 66, London (1969) Article 5.

11 Council of Europe, European Convention on the Protection of the Archaeological Heritage (revised), European Treaty Series 143, Valletta, Malta (1992) Article 1. 
12 Council of Europe, Helsinki Declaration on the political dimension of cultural heritage conservation in Europe, Fourth European Conference of Ministers responsible for the cultural heritage, 30-31 May, Helsinki (1996).

13 Ballester, J.M., 'Forward', in Policy and Law in Heritage Conservation, ed. R. Pickard, Spon Press, London and New York (2001).

14 Council of Europe, Compendium of Cultural Policies and Trends in Europe, 9th edn (2008), www.culturalpolicies.net (accessed 26 April 2008)

15 United Kingdom Institute for Conservation, Code of Ethics and Rules of Practice of the United Kingdom Institute for Conservation of Historic and Artistic Works, UKIC, London (1998) 3.

16 American Institute for Conservation (AIC), AIC Code of Ethics and Guidelines for Practice, AIC, Stanford (1998) 17.

17 Museums Association, Code of Ethics for Museums, Museums Association, London (2002).

18 International Council of Museums, ICOM Code of Ethics for Museums. ICOM, Seoul (2004).

19 Tite, M., 'Archaeological collections: invasive sampling versus object integrity', Papers from the Institute of Archaeology 13 (2002) 1-5.

20 Schadla-Hall, T., 'A response to invasive sampling versus object integrity', Papers from the Institute of Archaeology 13 (2002) $13-15$.

21 Merriman, N., 'A response to Michael Tite's paper on Archaeological collections: invasive sampling versus object integrity', Papers from the Institute of Archaeology 13 (2002) 6-8.

22 Reardon, K.K., Persuasion in practice, Sage Publications, California (1999) 126.

23 Hodgetts, R.M., Organizational Behaviour: Theory and Practice, Macmillan, USA (1991) 367

24 Harvard Business School, The essentials of power influence and persuasion, Harvard Business School Publishing Corporation, Boston (2006) 131.

25 Drummond, H., Introduction to Organizational Behaviour, Oxford University Press, Oxford (2000)

26 Handy, C., Understanding Organisations, 4th edn, Penguin, London (1999).

27 McKenna, E., Business psychology and organisational behaviour, Psychology Press, New York (2006)

28 Lustig, M.W., and Cassotta, L.L., 'Comparing group communication across cultures: leadership conformity, and discussion procedures', in Small group communication: theory and practice, ed. R.S. Cathcart, L.A. Samovar and L.D. Henman, Brown and Benchmark, Madison and London (1996) 316-326.

29 Gass, R.H., and Seter, J.S., Persuasion, social influence and compliance gaining, Allyn and Bacon, Massachusetts (1999).
30 Henderson, J., 'Influence: The impact of Language, Credibility and Gender', The Conservator 29 (2006) 63-72.

31 Perloff, R.M., The dynamics of persuasion, Lawrence Erlbaum Associates, New Jersey (1993)

32 Shimanoff, S.B., and Jenkins, M.M., 'Leadership and gender: challenging assumptions and recognizing resources', in Small group communication: theory and practice, ed. R.S. Cathcart, L.A. Samovar and L.D, Henman, Brown and Benchmark, Madison and London (1996) 327-344.

33 Bedell, G., 3 steps to yes: the gentle art of getting your way, Crown Business, New York (2000).

34 Cialdini, R.B., Influence: the psychology of persuasion, Morrow, New York (1993).

35 Slovic, P., Fischhoff, B., and Lichtenstein, S., 'Response mode, framing and Information processing Effects in Risk Assessment' in The Perception of Risk, ed. P. Slovic, Earthscan, London (2000) 154-167.

36 Museums Association. Making collections Effective Including Effective collections: an introduction Collections for the future two years on, Museums Association, London (2007).

37 House of Lords, Science and Technology Committee. Science and Heritage Report with Evidence. 9th Report of Session 2005-2006, House of Lords, The Stationery Office Limited, London (2006).

\section{AUTHORS}

Jane Henderson is a fellow of the International Institute for Conservation and an accredited member of Icon. She has been working in, and studying, conservation and collections care in Wales since 1984. She has a BSc in archaeological conservation and an MSc in collections care. Jane has worked in conservation in both the public and private sectors, including acting as conservation manager for the Council of Museums in Wales. Jane now teaches on Cardiff University's BSc in conservation and MSc in collections care. Jane is the stewardship representative on the Welsh Federation of Museum and Art Galleries and edits the Conservation Matters in Wales conferences. Address: School of History and Archaeology, Cardiff University, Humanities Building, Colum Drive, Cardiff, CF10 3EU, Wales. Email: HendersonLJ@cardiff.ac.uk

Panagiota Manti is a $\mathrm{PhD}$ research student in conservation in the School of History and Archaeology at Cardiff University working on the technology, decoration and corrosion of Greek bronze helmets. She has an MSc in archaeological science from the Research Laboratory in History and Arts, Oxford University, and a BSc in conservation from Cardiff University. Panagiota has been active in the field of archaeological conservation since 1995, after receiving a diploma in conservation from a private institute in Greece. Her latest work involves the technology of faience production and the use of non-destructive synchrotron- and neutron-based methods for investigation of archaeological bronzes and the detection of tinning. Address: as for Henderson. Email: mantip@cf.ac.uk 